\title{
Remanufacture of rotary tables for heavy duty machine tools
}

\author{
Dan Prodan ${ }^{1}$, Anca Bucuresteanu ${ }^{2}$, Adrian Motomancea ${ }^{3, *}$, and Alina Ovanisof ${ }^{4}$ \\ ${ }^{1}$ Robots and Production Systems Department, University Politehnica of Bucharest, 313 Splaiul Independenţei, 060042, Romania \\ ${ }^{2}$ Robots and Production Systems Department, University Politehnica of Bucharest, 313 Splaiul Independenţei, 060042, Romania \\ ${ }^{3}$ Assoc. prof., Mechanics Department, University Politehnica of Bucharest, 313 Splaiul Independenţei, 060042, Romania \\ ${ }^{4}$ University assistant, Mechanics Department, University Politehnica of Bucharest, 313 Splaiul Independenţei, 060042, Romania
}

\begin{abstract}
In this paper, the authors present some of the theoretical and experimental research conducted on the occasion of rotary tables remanufacturing for $\mathrm{CNC}$ machine tools belonging to Boring and Milling Machines family. They give the constructive solutions applied on CNC machines and the specific systems of guiding, locking and driving. The authors present also the modifications required when passing from CC variant to $\mathrm{CNC}$ variant in terms of locking - indexing systems and hydraulic suspension systems. The paper presents different achievements but insists particularly on the remanufacture of the rotary table with useful area 1700x2000 mm with longitudinal travel of $1000 \mathrm{~mm}$ (MRD 1700x2000/1000).
\end{abstract}

\section{Introduction. Rotary tables for machine tools}

The rotary tables [1] are part of the structure of conventional or $\mathrm{CNC}$ machine tools. In the case of conventional machine tools, the rotary tables make possible the circular positioning of the blanks to be machined in specific conditions of accuracy and stiffness, with accurate stop every $90^{\circ}$. As for CNC machines, under certain conditions of accuracy, the rotary tables can ensure a circular feed movement besides the positioning movement. In the case of the boring and milling machines (AF type) this feed movement, usually noted as "B" axis, can operate independently or within some interpolations with other numerically controlled axes.

The paper is addressed to designers and companies whose object of activity is the manufacture and remanufacturing of machine tools. It is known that, at present, machine tools produced 10 or even 20 years ago are modernized according to the requirements of modern industry. The research can be a real support for the remanufacturing of conventional rotary tables and their transition to the necessary level of CNC systems.

\section{Remanufacture of the rotary table MRD 1700x2000/1000}

The remanufactured rotary table is CC type with limited possibilities of translation and rotation in terms of accuracy. The maximum accepted load is 15 to. The intention was to manufacture a CNC table with possibilities of linear positioning and machining and only circular positioning. As the linear travel is performed by means of a ball screw, and the rotation movement - by means of a crown and pinion double system with backlash mechanical takeover, it was found out that the remanufacturing was possible. In these conditions, the translation movement can be correlated with other movements of the associated machine (AF boring and milling machine) for making interpolations. Because the intended rotation movement was for positioning only, it was not necessary to have the equipment required to achieve the interpolation of this axis. After the positioning, the table will be blocked.

Figure 1 shows the kinematic diagram of the remanufactured rotary table [2].

The notations used in fig. 1 are the following ones:

1, 11- electric drive motors $\left(\mathrm{EM}_{1}\right.$ and $\left.\mathrm{EM}_{2}\right), 2,12$ reducers $\left(R_{1}\right.$ and $\left.R_{2}\right)$ with transfer ratios " $i_{1}$ " and " $i_{2}$ ", 3 -toothed belt gearing, 4- worm/worm gear transmission, 5 - system of return backlash takeover, 6-guideways of the saddle, 7-system of locking/unlocking, 8- rotary table (RT), 9-rotary table supporting on bearings, 10- rotation transducer, HI- hydraulic unit, $Z_{1}, Z_{2}$-number of teeth of belt pulleys, q, q'-number of worm starts (q=q'), Z, Z'teeth number of worm gears $\left(Z=Z^{\prime}\right), n_{0}-n_{6}$-rotational speed of shafts I-VI, $D_{M^{-}}$average diameter of axial guideways surface, $\mu$-coefficient of friction of circular guideways - rotary table assembly, 13-ball screw, 14saddle, 15-position sensor, 16- hydrostatic pockets, ppitch of the leading screw.

The rotary movement of the table is performed by means of the electric motor 1 [2,3], coupled to reducer 2 that rotates the table $\mathrm{RT}$ via the toothed belt gearing $\mathrm{Z}_{1} / \mathrm{Z}_{2}[4,5]$, of the worm/worm gear mechanism $\mathrm{q} / \mathrm{Z}$ and the inner gearing $Z_{3} / Z_{4}$. The table is centered by radial bearings [6] and is supported on the hydrostatic thrust bearing. As soon as the rotation is finished, it is compulsory to lock the table by means of the cylinders 7 . It is reccommended to use mechanical locking and

Corresponding author: motom $@$ deltainfo.ro 
hydraulic unlocking [7]. If the rotary table makes a feed movement too, the locking system 7 may disappear. In this case, the intended position is maintained by the motor and the control system, obtaining what is called "hold axis". To reduce the return backlash in the case of circular feed movement it is compulsory to have a backlash takeover system.

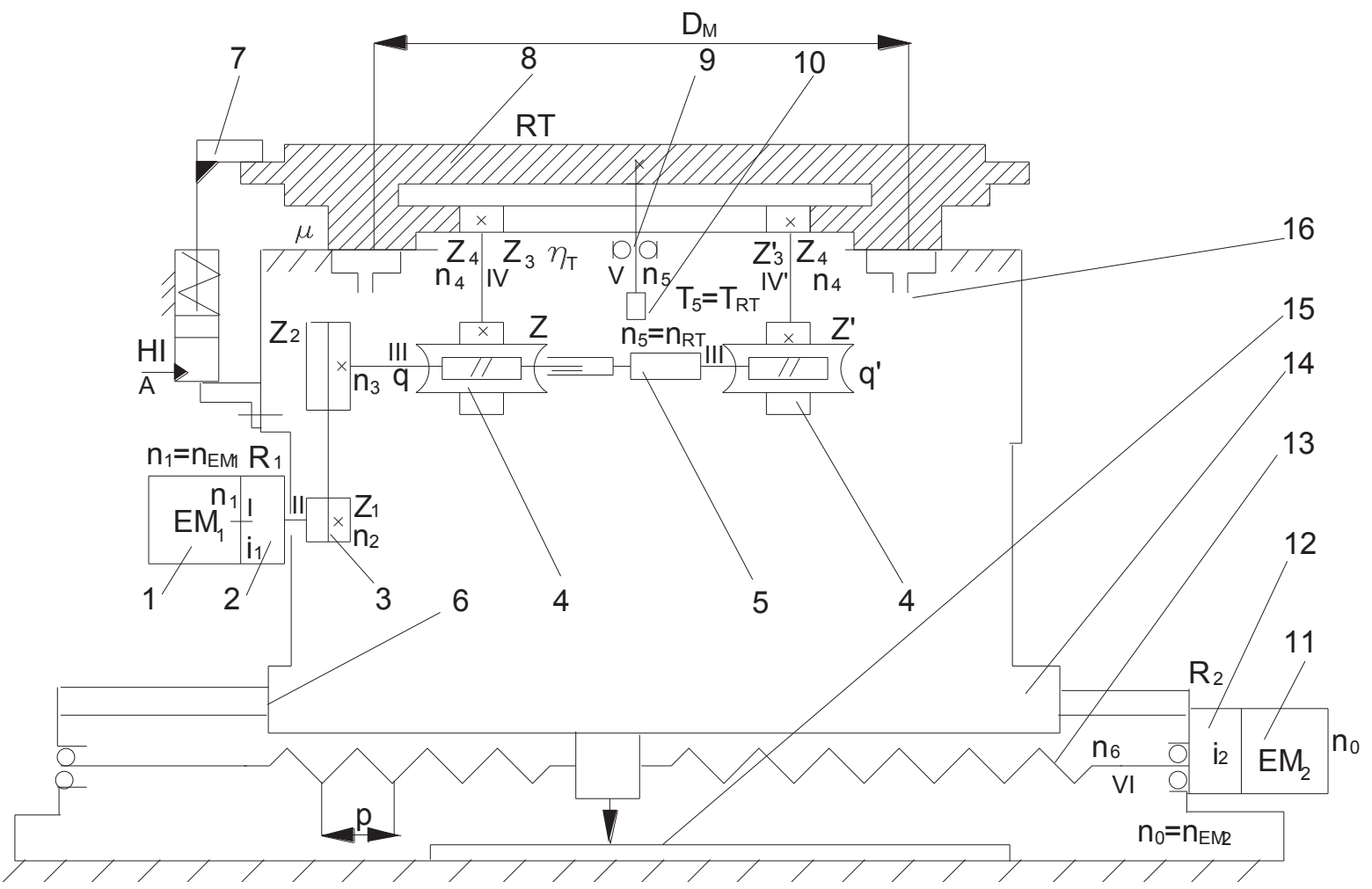

Fig. 1. Kinematic diagram of the rotary table.

Table movement is obtained from two pinions identical as module and number of teeth, denoted $Z_{3}$ and $Z_{3}$, which gear with the inner toothed gear $Z_{4}[5]$. The translational motion is made by means of the motor $\mathrm{EM}_{2}$ $[2,3]$ which, via the reducer $R_{2}$ (transfer ratio $i_{2}$ ), drives the ball screw $13[4,5]$. This one moves the saddle 14 . The position of the saddle is read by the translational transducer 15. For the rotational and translational motion it shall be considered:

$$
\begin{gathered}
n_{R T}=n_{1} \cdot i_{1} \cdot \frac{Z_{1}}{Z_{2}} \cdot \frac{q}{Z} \cdot \frac{Z_{3}}{Z_{4}} \\
v=n_{0} \cdot i_{2} \cdot p
\end{gathered}
$$

In the equation (2) it was noted with "v" the translational speed of the saddle.

The speed will be adjustable in the range of $0-4$ $\mathrm{m} / \mathrm{min}$. The speed of the rotary table (nRT) is also adjustable in the range that ensures a peripheral speed, in the hydrostatic pockets area, in the same range (0-4 $\mathrm{m} / \mathrm{min}$ ).

In terms of mechanics, the remanufacturing involves: 1-remanufacture of translational and rotational guideways,

2-adjustment of the backlash takeover system at table rotation.

\section{Remanufacture of rotary table guideways [8]}

Plastics (polyamides) are used successfully in the construction of guideways for machine tools, replacing metals such bronze and cast iron. Due to their composition, (plastics with fillers such as bronze, glass, graphite, molybdenum disulphide (MoS2), ceramic or a mixture of them) they have a coefficient of friction $0.003-0.05$ higher than bronze which is 0.05 in optimal conditions.

Maximum working speeds can exceed $2 \mathrm{~m} / \mathrm{s}$ [6], which is more than the speed required for heavy duty machine tools whose rapid travel speed rarely exceeds $10 \mathrm{~m} / \mathrm{min}$.

There are also other benefits [9]:

- total elimination of the risk of seizing and of scratches apparition,

-diminution of the wear of counterparts especially if these ones are made of cast iron,

-decrease of ferrous materials consumption, which are more expensive than plastics,

-diminution of workload and intervention time in case of reconditioning (remanufacturing),

- resistance to corrosive agents allowing to be used for closed guideways and for open ones as well ( with and without Covers) [10], 
- the behavior of these materials at low speeds is very good, eliminating the danger of stick-slip (Stick-Slip Effect)[11].

Among the specific disadvantages we can mention: -they make a thermal insulation of the guideways and do not allow their cooling but only at very high speeds, which is not the case of heavy duty machine tools, -they require specific conditions of assembling and machining,

-in case of faulty clamping or sticking, their peeling can occur over time.

For the guideways of translation and for those of rotation (B) there were chosen two materials of different colors [12], with the following common features:

Colour in etched delivery condition: medium to dark brown or white

Colour after mechanical machining: grey

Water absorption: $<0.01 \%$

Linear coefficient of expansion: 6 x 10-5 1/K

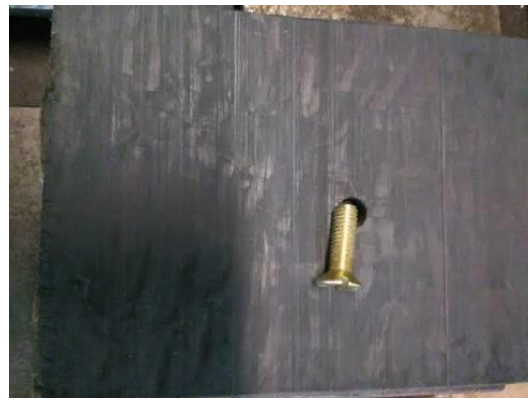

a. Material used for rotational guideways
Max. pressure load for $1 \%$ deformation: $930 \mathrm{~N} / \mathrm{cm}^{2}$

Hardness: HRC $60 \pm 5$ Shore D

Modulus of elasticity: $1.000 \mathrm{~N} / \mathrm{mm}^{2}$

Figure 2 shows samples of the materials used and one of the clamping screws (made of brass).

On the occasion of the introduction of plastic guideways, it was measured their hardness but also the hardness of the metallic guideways that were kept. In the case of the translational axis guideways (W) and of the rotational axis (B) there were performed the measurements shown in table 1 .

By introducing plastic elements, the hardness of the metallic guideways is not so important, especially for the axis of rotation " $\mathrm{B}$ " where, due to the hydrostatic suspension, the metal/plastic friction is virtually impossible. It can appear only in degraded mode, when the hydrostatic unit does not operate.

Figure 3 shows the guideways made of plastics after manual processing ( scraping).

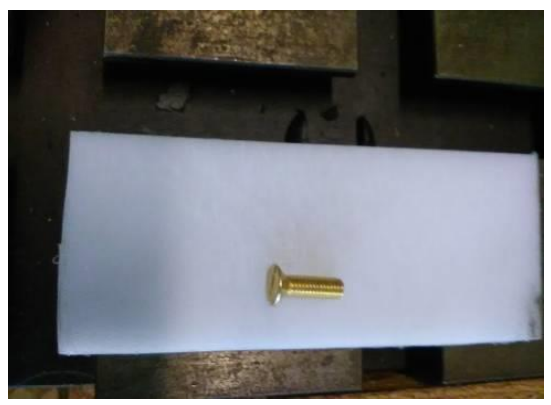

b. Material used for translational guideways

Fig. 2. Materials used for remanufactured guideways (Photographer : D. Prodan).

Table 1. Characteristics of the guideways made of plastic materials

\begin{tabular}{|c|c|c|c|}
\hline Application & No.of.Spots in 25sq.Area & Surface finish $\mathrm{R}_{\mathrm{a}}$ microns & Harder \\
\hline $\begin{array}{c}\text { Guideways for W axis } \\
\text { STEEL NO Scraping }\end{array}$ & $8-11$ & $0.4-0.8$ & $45-48 \mathrm{HRC}$ \\
\hline $\begin{array}{c}\text { Guideways for W axis } \\
\text { STEEL NO Scraping }\end{array}$ & $8-11$ & $0.4-0.8$ & $45-48 \mathrm{HRC}$ \\
\hline $\begin{array}{c}\text { Guideways for B Axis Cast } \\
\text { IRON after Scraping }\end{array}$ & $9-11$ & 1.6 & $160 \mathrm{HB}$ \\
\hline
\end{tabular}

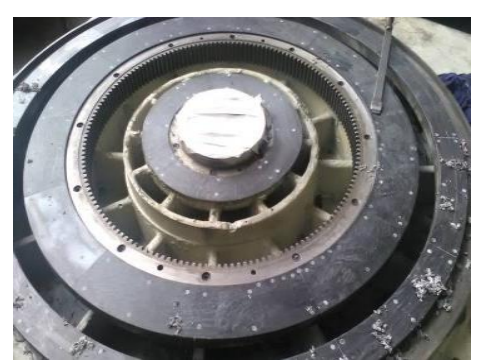

a. Rotational guideways

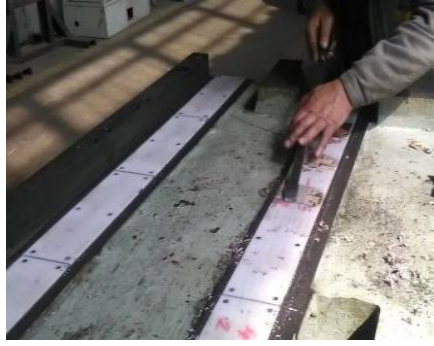

b. Translational guideways

Fig. 3. Guideways made of plastics (Photographer : D. Prodan). 

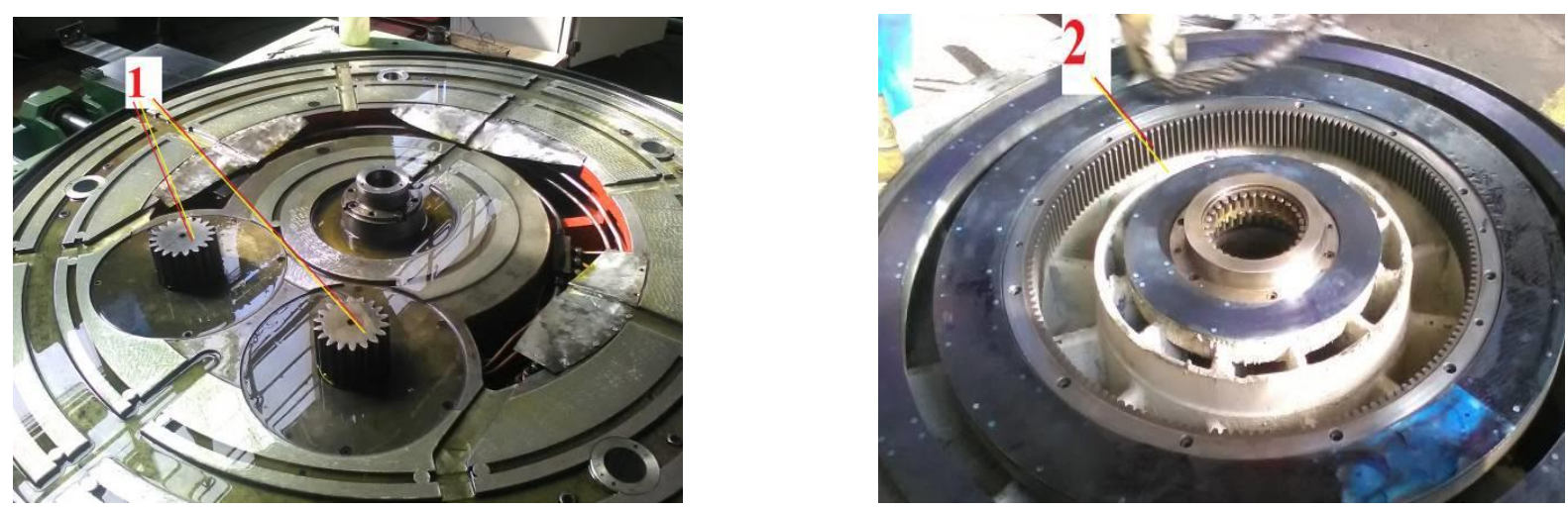

Fig. 4. Positioning of pinions and crown gear (Photographer : D. Prodan).

On the occasion of the remanufacturing, the rotary table was disassembled, the bearings were replaced and the backlash takeover system for rotational motion was adjusted again. The system is formed of two gearings worm-worm gear (4 in fig.1). The worms are mechanically preloaded, with disk springs (5 in fig. 1 ), after making the gearing between pinions and crown.

Figure 4 shows the positioning of pinions (1) and crown gear (2) before the final assembling.

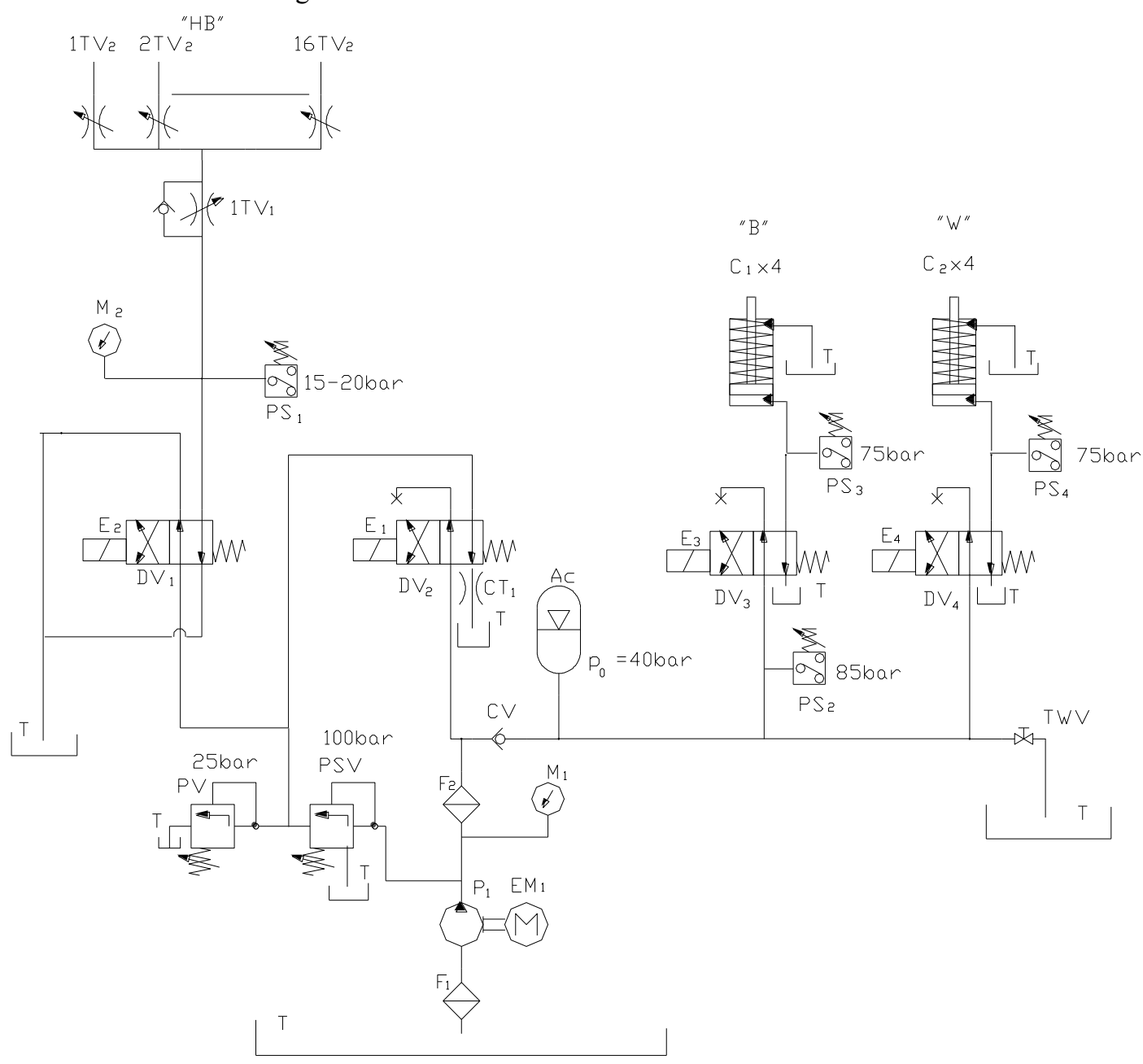

Fig. 5. Original hydraulic diagram of the rotary table MRD1700-2000/100. 
Pump $\mathrm{P}_{1}$, driven by the electric motor $\mathrm{EM}_{1}$, sucks oil through the suction filter $F_{1}$ of the tank $T$, located in the saddle of the rotary table. The oil is filtered by the pressure filter $F_{2}$. The maximum pressure in the unit during unlocking stages is adjusted by means of the pressure sequence valve, adjusted at the pressure of 100 bar. The maximum pressure for the system of hydrostatic suspension is regulated by means of the pressure valve PV. The circuits of low and high pressure are separated by the check valve CV. The accumulator Ac is located in the high pressure circuit meant to unlock the axes of translation and rotation. The actuation of the electromagnets E3 and E4 of the directional valves DV3 and DV4 leads to the unlocking of rotation and translation. The locking is made by four cylinders $\mathrm{C} 1 \mathrm{x} 4$ and four cylinders $\mathrm{C} 2 \mathrm{x} 4$. The unlocked status is confirmed by the pressure switches $\mathrm{PS}_{3}$ and $\mathrm{PS}_{4}$ respectively, adjusted at the pressure of $75 \mathrm{bar}$. The general pressure in the circuit of the accumulator [13] is confirmed by the pressure switch $\mathrm{PS}_{2}$, adjusted at the pressure of 85 bar. To activate the circuit of rotary table hydrostatic suspension it is necessary to drive the electromagnets E1 and E2 of the directional valves Dv1 and DV2. The pressure in this circuit is confirmed by the pressure switch $\mathrm{PS}_{1}$. The general flow used in the hydrostatic system is regulated by means of the throttle valve 1TV1. The flow in the 18 pockets is adjusted by the throttle valves 1TV2-16TV2. The pressure during operation is viewed on the manometers M1 and M2. On the path "T" of the directional valve DV2 is located a cartridge throttle CT1. If eventual interventions in the circuit with accumulator are needed, there is a two ways valve TWV. The pump supplies a flow rate of $Q_{p}=6 \mathrm{l} / \mathrm{min}$. In these conditions, the maximum power consumption is $\sim 1.5 \mathrm{~kW}$.

For remanufacturing it is considered that the introduction of the entire hydraulic unit in the saddle is not the best solution given that the warming of the saddle may lead to impaired accuracy of the machine. Warming is also facilitated by the relatively small volume of oil and the high operating pressure necessary for unlocking.

Taking into account these observations and the passage from a $\mathrm{CC}$ machine to a $\mathrm{CNC}$ machine, a new hydraulic unit was designed; it is formed of two systems, entirely separated, intended for unlocking and for hydrostatic suspension.

In figure 6 is presented the hydraulic diagram of the unlocking system of the translation and rotation axes.

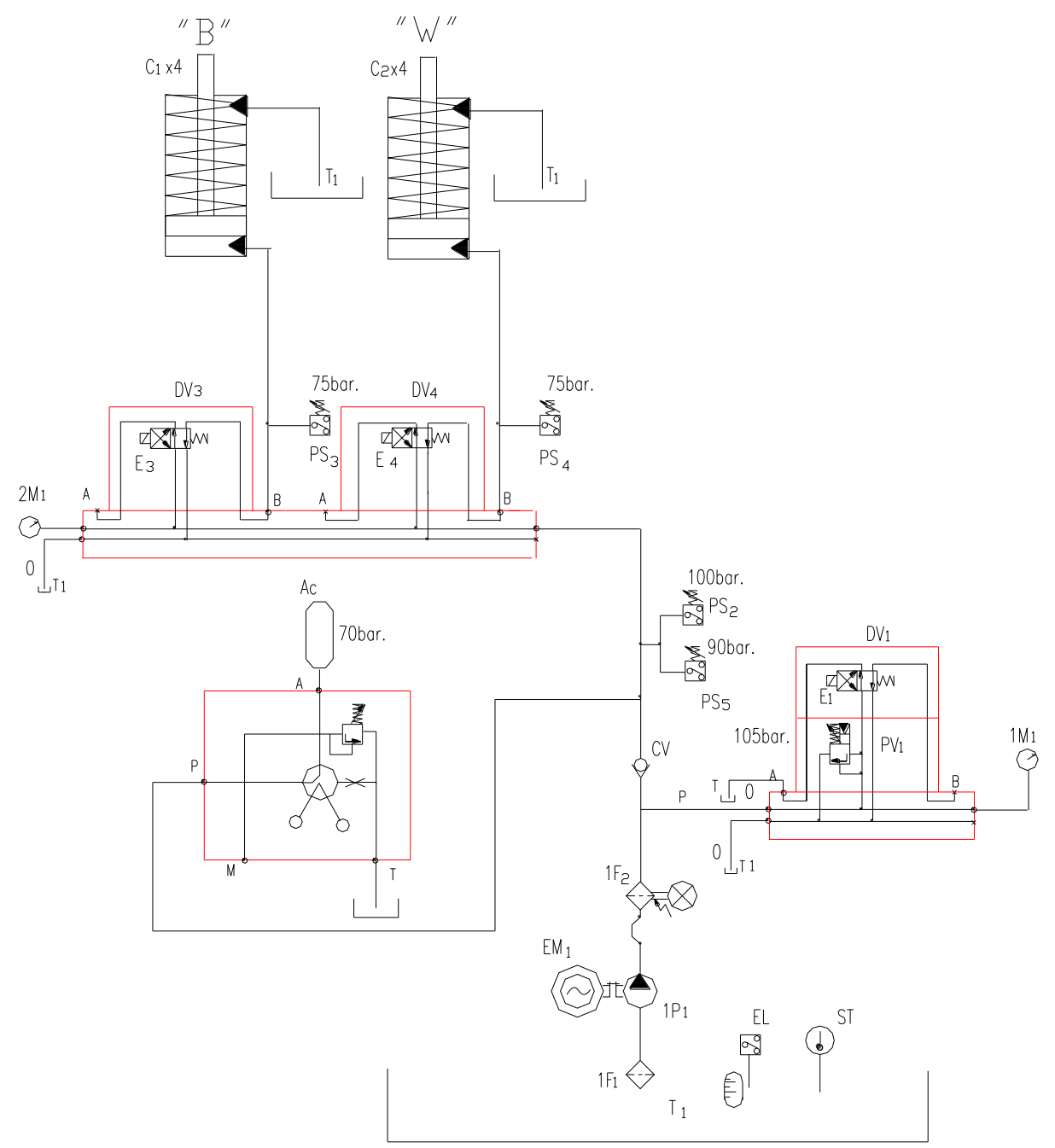

Fig. 6. Hydraulic diagram for the unlocking system of the machine MRD1700x2000/1000 CNC.

\footnotetext{
Corresponding author: motom $@$,deltainfo.ro
} 
Pump $1 \mathrm{P}_{1}$, driven by the electric motor $\mathrm{EM}_{1}$, sucks the oil through the suction filter $1 F_{1}$ in the tank $T_{1}$. The oil, filtered by the filter $1 \mathrm{~F}_{2}$ (equipped with electric clogging indicator) is sent to the unit. The maximum pressure is adjusted by the pressure valve $\mathrm{PV}_{1}$. The circuit of the accumulator Ac is powered via the oneway check valve CV. The pressure switches $\mathrm{PS}_{2}$ and $\mathrm{PS}_{5}$ too are located on this circuit. The actuation of the electromagnet $\mathrm{E} 1$ of the directional valve DV1 enables the circuit of the accumulator to load up to the pressure adjusted at the pressure switch $\mathrm{PS}_{2}$ (100bar). When this pressure is reached, the actuation of the directional valve DV1 is stopped. In this case, the pump overflows freely to the tank, with low energetic consumption.

By driving the electromagnets E3 and E4 from the directional valves DV3 and DV4 it results the unlocking of the axes "B" and "W", respectively. The unlocking is confirmed by the pressure switches $\mathrm{PS}_{3}$ and $\mathrm{PS}_{4}$. If after this unlocking the pressure in the circuit of the accumulator drops below the pressure adjusted at the pressure switch $\mathrm{PS}_{5}$ (90 bar), the electromagnet $\mathrm{E} 1$ of the directional valve DV1 shall be actuated again. After achieving the unlocking, the pressure circuit is reloaded at a pressure of 100 bar and the motor EM1 shall be stopped if no new unlocking is commanded in one minute. The pressures are permanently viewed by means of the manometers 1M1 and $2 \mathrm{M} 1$. So it is possible to reduce the energetic consumption and the risk of overheating the system. The level gauge EL shows if there is a minimum level of oil. The oil temperature is measured continuously using the thermal probe ST. All the system is made as an independent hydraulic unit outside the machine.
To achieve the hydrostatic suspension [4,5,7] necessary for table rotation, it was made a simple unit, located right in the machine saddle. The hydraulic diagram of this unit is shown in figure 7.

To make the hydrostatic suspension it is necessary to start the motor $\mathrm{EM}_{2}$. This one drives the pump $2 \mathrm{P}_{1}$ which, by means of the suction filter $2 \mathrm{~F}_{2}$, sucks the oil from the tank $\mathrm{T}_{2}$, installed right in the saddle. The oil filtered by the filter $2 \mathrm{~F}_{2}$ is sent to the unit. The maximum working pressure is adjusted using the pressure valve $\mathrm{PV}_{2}$. The working pressure is read on the manometer $1 \mathrm{M}_{2}$. The suspension can be activated by connecting to power supply the electromagnet E2 of the directional valve DV2. The flow value is set via the throttle 1TV1. The confirmation of the pressure required by the suspension is made by the pressure switch $\mathrm{PS}_{1}$. The fixed throttles 1-16TV2 adjust the oil needed for every pocket. An electric indicator for low level and a thermal probe are assembled on the tank. In the case of repeated positioning followed by short term locking-unlocking, the electric motor must be left to run full time and only the electromagnet E2 shall be driven. As soon as the intended position is reached and the locking is performed, the motor EM2 will be stopped too. If "B" becomes the working axis, the motor and the electromagnet will operate full time. After locking, if no other command is given, after 1 minute the electric motor will be stopped by the program. It these working conditions are applied, the saddle (that includes the tank and the entire unit) shows no warming threat.

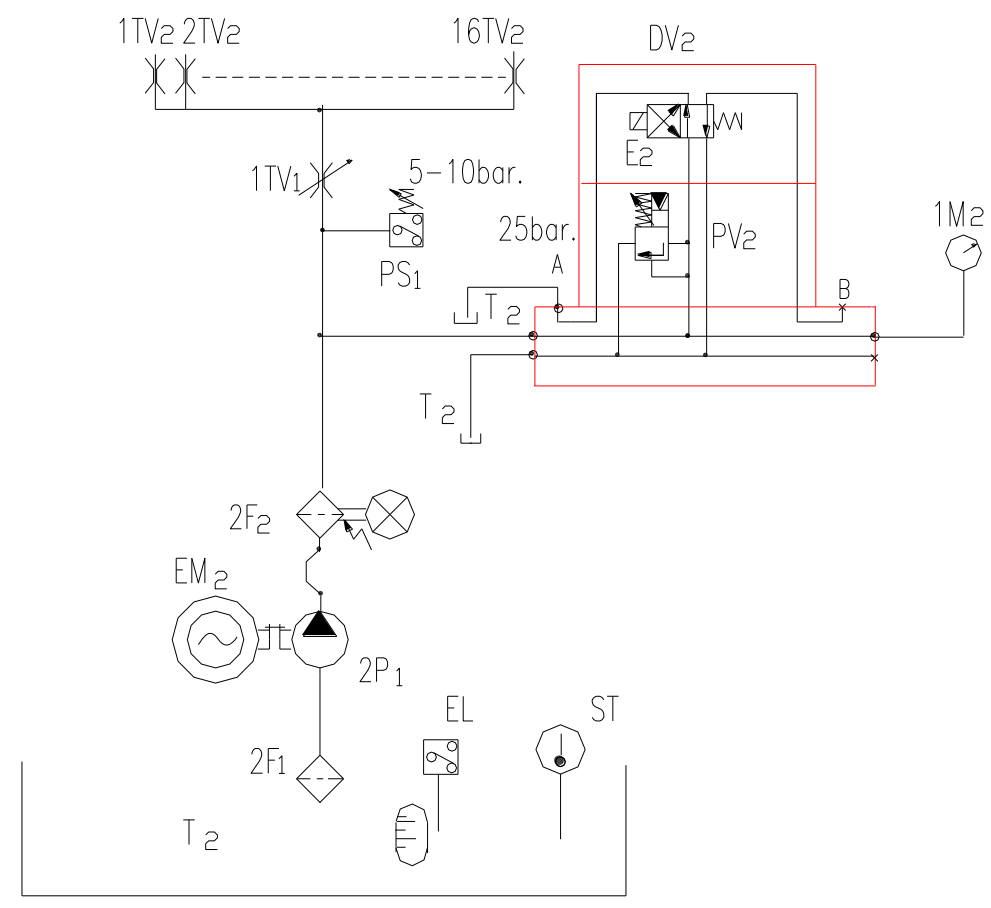

Fig. 7. Hydraulic diagram of the suspension unit of MRD 1700x2000/1000 CNC. 


\section{Mathematical modeling and simulation of hydraulic units operation of MRD 1700x2000/1000 CNC machine}

For modeling and simulating the hydrostatic suspension system operation, it was considered that for each one of the 16 pockets $[4,5,7]$, it is possible to define pressure $\left(\mathrm{p}_{\mathrm{P}}\right)$ and flow $\left(\mathrm{Q}_{\mathrm{P}}\right)$, as shown in the calculation scheme in figure 8 and the equations:

$$
\begin{aligned}
& p_{p}=\frac{W}{L \cdot l \cdot\left(1-\frac{a}{l}\right)} \\
& Q=\frac{L \cdot h^{3} \cdot p_{p}}{6 \mu \cdot a}
\end{aligned}
$$

In figure 8 and equations (3) and (4) were made the following notations: $p_{\mathrm{P}}$-pressure in pocket, $\mathrm{p}_{\mathrm{S}}$-pressure of source (max. 25bar), L, 1, a - sizes that define the pocket, W-load corresponding to pocket (theoretically $\mathrm{W}=\mathrm{G} / 18$ where $\mathrm{G}$ is the semi-finished product and table weight), h-thickness of the oil film, Q-flow discharged from the pocket $\left(18 \mathrm{Q}<\mathrm{Q}_{\mathrm{P}}\right.$, where $\mathrm{Q}_{\mathrm{P}}$ is the pump flow), $\mu$-dynamic viscosity of the oil used. The calculation took into consideration a thickness of the oil film of $\mathrm{h}=0.25 \mathrm{~mm}$. In these conditions, by simulation, using specialized programs, the characteristics shown in figures 9 will be obtained for the pressures $\mathrm{p}_{\mathrm{S}}$ and $\mathrm{p}_{\mathrm{P}}$.

In the case of this machine one can measure only the pressure at the source because it is not possible to assemble manometers in each pocket. The real pressure viewed on the manometer $1 \mathrm{M} 2$ is of $\sim 13.5$ bar. In these circumstances, taking into account the multitude of factors that influence the operation of the unit (ambient temperature, shape of throttles, variations of viscosity depending on temperature etc.), we can consider that the results of simulation are satisfactory.

The simulation of the hydraulic unit intended for the unlocking allows, among other things, to determine the time needed to charge the accumulator circuit and to make the unlocking. In terms of unlockings, these are considered to be done only with the oil reserve existing in the accumulator charged with $\mathrm{N}_{2}$ at $\mathrm{p}_{0}=70$ bar. The time required to fully charge the accumulator, according to the characteristic in figure 10 , is $\sim 4 \mathrm{~s}$.

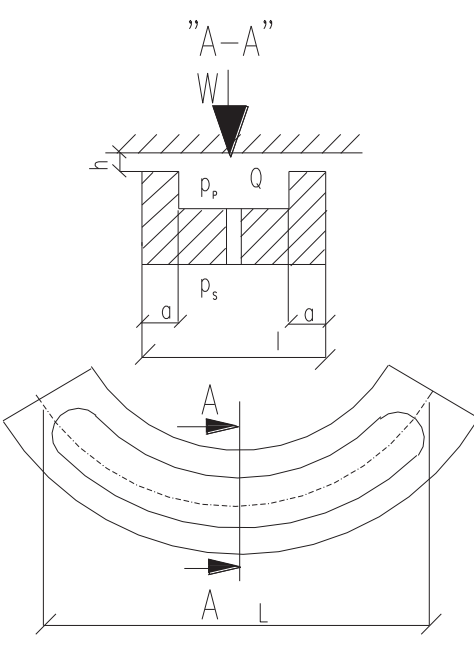

Fig. 8. Calculation scheme of hydrostatic pockets

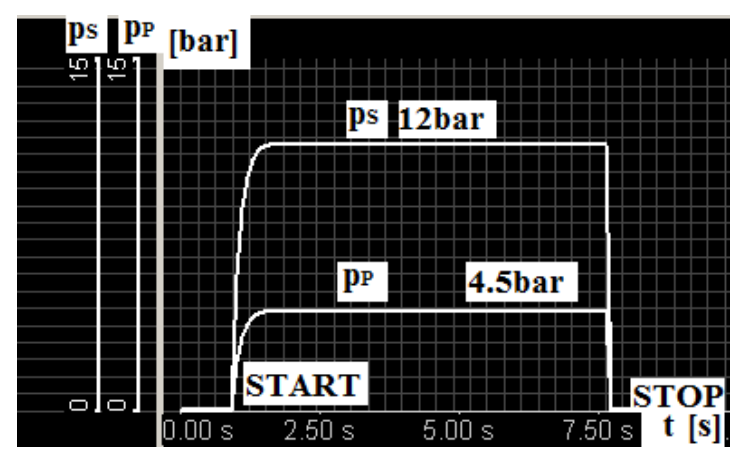

Fig. 9. Evolution of pressures $\mathrm{p}_{\mathrm{S}}$ (at source, measurable with manometer $1 \mathrm{M} 2$ ) and $\mathrm{p}_{\mathrm{P}}$ (average pressure in pockets). 


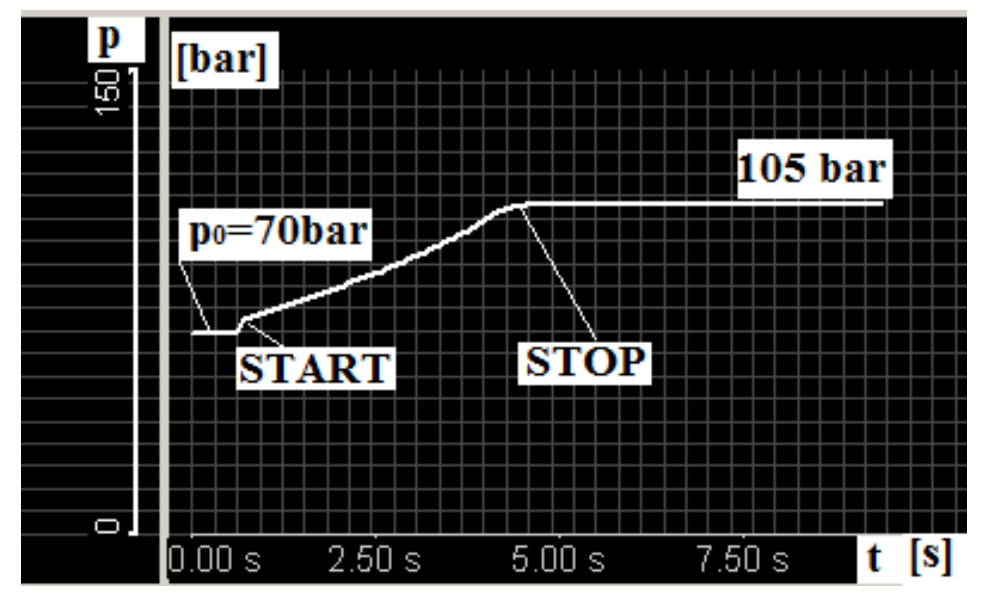

Fig. 10. Accumulator charge time from the pressure of $\mathrm{p}_{0}=70$ bar to the maximum pressure of 105 bar.

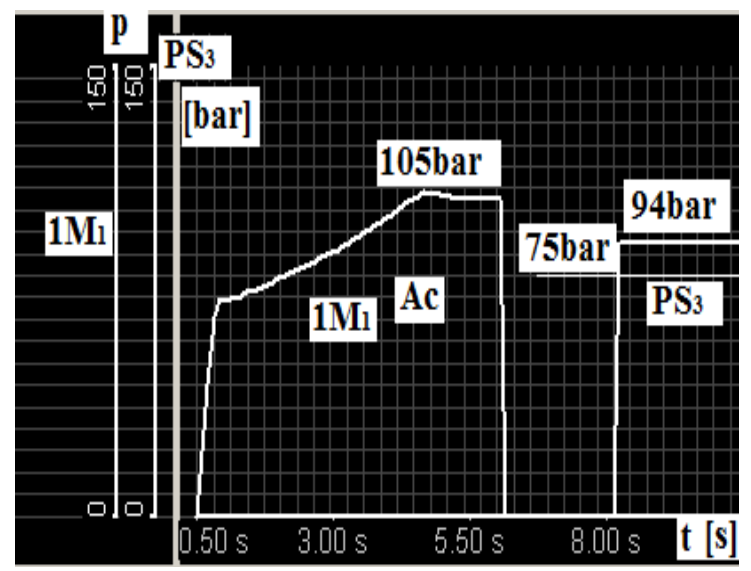

a. Unlocking of " $\mathrm{B}$ " axis

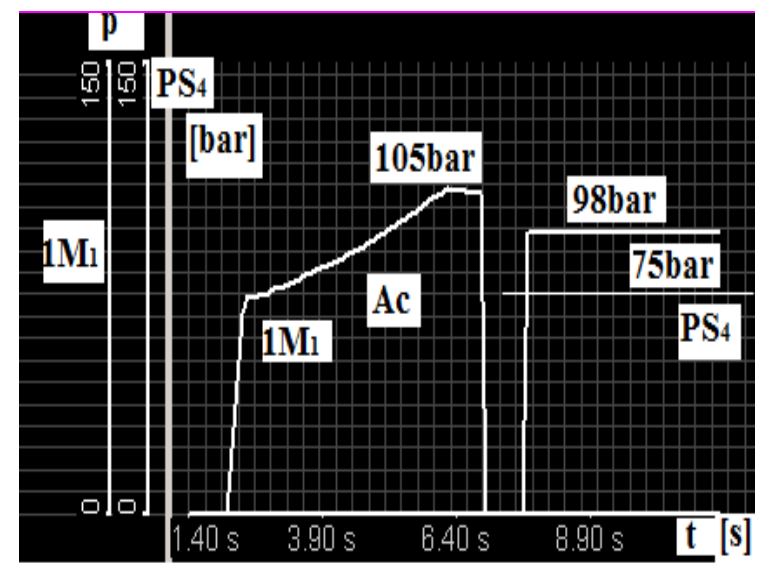

b. Unlocking of "W" axis

Fig. 11. Unlocking of "B" axis and "W" axis only from accumulator.

In reality, according to the measurements performed, about $5 \mathrm{~s}$ are needed to charge the accumulator, value very close to the one resulted from simulation.

The cylinders designed for the unlockings $\mathrm{C} 1$ and C2 are different; this fact explains why the times required for unlockings - using the same unit and the same conditions (with accumulator oil reserve only) are different, as per the characteristics in figure 11.

From the characteristics presented in figure $11 \mathrm{a}$ it results that the unlocking of " $\mathrm{B}$ " axis is made in 2 s. This unlocking is achieved at 94 bar, but is confirmed at 75 bar by the pressure switch $\mathrm{PS}_{3}$. In fact, the unlocking is made in $4 \mathrm{~s}$, at a pressure of $\sim 90$ bar.

In the case of "W" axis unlocking, using only the accumulator, it can be observed that the pressure in circuit reaches the value of 98 bar; the unlocking is confirmed at the pressure of 75 bar by the pressure switch $\mathrm{PS}_{4}$. The unlocking time resulted from simulation is $1 \mathrm{~s}$. In reality it is $\sim 3 \mathrm{~s}$.

\section{New hydraulic unit of the table MRD1700x2000/1000}

As mentioned before, the table MRD1700x2000/1000 $\mathrm{CNC}$ has two hydraulic units after remanufacturing. The first one appears as an independent unit related to the machine and is meant to unlock " $\mathrm{B}$ " and " $\mathrm{W}$ " axes after command. Figure 12 shows the unit for unlockings, keeping the same notations as in figure 6 .

The unlocking cylinders, noted by $\mathrm{C}_{1} \mathrm{x} 4$ and $\mathrm{C}_{2} \mathrm{x} 4$ in the diagram, are supplied from this unit, via two hoses. The tank of this unit has a useful volume of 701 . To achieve the table suspension there is a second hydraulic unit (with diagram in figure 7) located right in the saddle. Its volume is $\sim 601$. The pump $2 \mathrm{P} 1$ is driven by a motor with the power of $0.55 \mathrm{~kW}$ and the rotational speed of 1500 RPM. We mention again that the power of the initial motor used at $\mathrm{CC}$ variant was of $1.5 \mathrm{~kW}$. In the case of $\mathrm{CC}$ variant the motor operated full time, while in the remanufactured 
variant $(\mathrm{CNC})$ the motor operates only as long as the

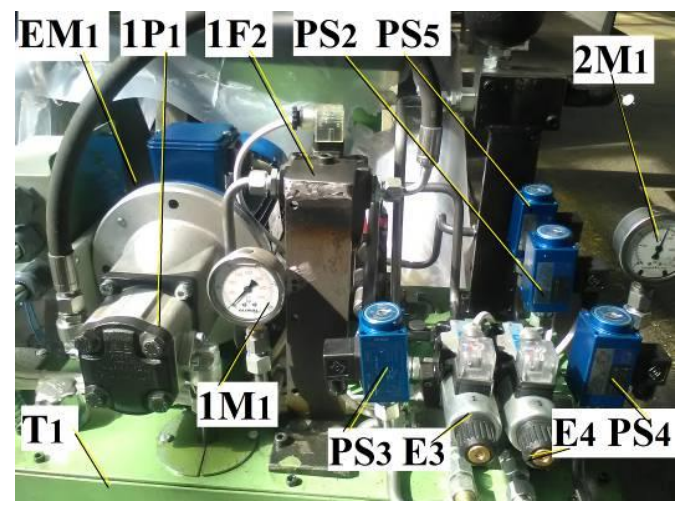

rotation is achieved.

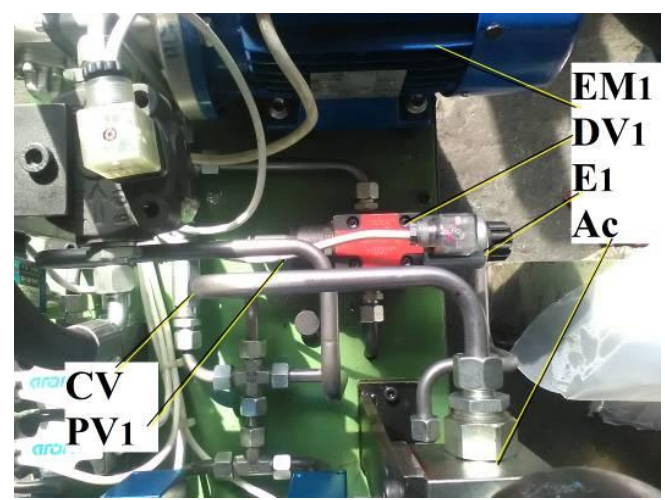

Fig. 12. Hydraulic unit for unlocking of working axes of MRD 1700x2000/1000 CNC (Photographer A. Motomancea).
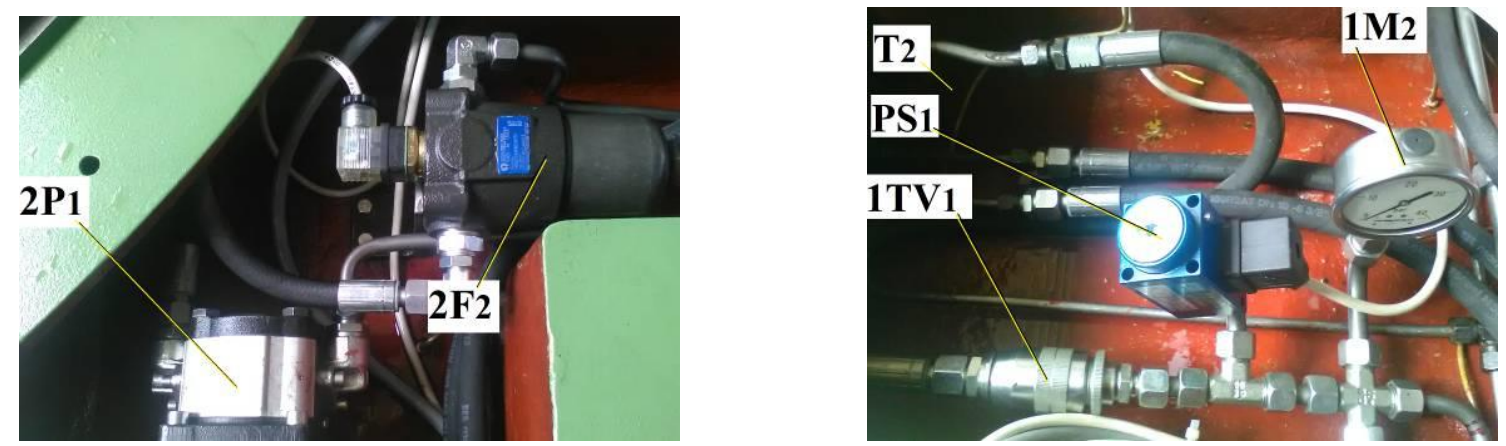

Fig. 13. Hydraulic unit for achievement of "B" axis suspension at MRD 1700x2000/1000 (Photographer A. Motomancea).

In figure 13 is shown the manufactured unit, keeping the same notations as in figure 7 .

\section{Conclusions}

The rotary tables can be used for positioning but also for machining operations of interpolation type on the boring and milling machines (AF) or the horizontal boring and milling machines (AFP). In the case of positionings by indexing, their accuracy is in the range of \pm 10 "- \pm 3 ". If the positioning is made from the numerical control (" $\mathrm{B}$ " axis) it is compulsory to use the systems for return backlash takeover. Usually, these systems include two worm/wormed gear mechanisms relatively tensioned. The presence of these mechanisms is mandatory if the rotary tables are remanufactured, which involves the passage from a $\mathrm{CC}$ machine to $\mathrm{CNC}$ machine. If " $\mathrm{B}$ " axis is the working axis and can operate by interpolation with other axes, the presence of the backlash takeover system is binding.

During remanufacturing, a special attention shall be given to guideways reconditioning. It is recommended to use plastics coated guideways. For heavy loads but also for an easier driving it is recommended to use the hydraulic suspension. There are tables which use this

suspension for rotation only, but there are cases when the same solution is used for translations too. The thickness of the oil film depends on the machine type and the weight of the blank. Usually, this thickness is $2 / 100-3 / 100 \mathrm{~mm}$. It is not advised to have thicknesses of less than $1 / 100 \mathrm{~mm}$ because there is the risk of seizing. The films too thick are not recommended either because they reduce the stiffness of the machine- blank system throughout the machining operations.

Taking into account the large masses in movement, a dynamic calculation is required besides the static calculation. To achieve the desired torque and rotational speed, one must use toothed gear reducers (with ratio in the range $1 / 4-1 / 2$ ), planetary reducers (reduction ratio reaching even 1/9), worm/wormed gear mechanisms (reduction ratio starting from $1 / 20$ ).

The hydraulic units of the rotary tables will be made so that the thermal effects of their operation do 
not influence the accuracy of positioning and machining.

By remanufacturing the $\mathrm{CC}$ rotary tables to transform them in $\mathrm{CNC}$ variant and by associating them with $\mathrm{CNC}$ machine tools it is possible to obtain machining systems with an increased number of numerically controlled axes, allowing the machining of complex parts for various industrial branches.

\section{References}

1. D. Catrina, A. Totu, S. Croitoru, G. Carutasu, N. Carutasu, A. Dorin, Flexibile systems for cutting machining operations (MatrixROM Publishing House, Vol 1, Bucharest, ISBN 973-685-981-9, 2005)

2. D. Prodan, A. Bucuresteanu, T. Dobrescu, A. Motomancea, Rotary tables for machine tools (Applied Mechanics and Materials Submitted: 2016-01-12 ISSN: 1662-7482, Vol. 841, pp 168172, 2016)

3. ****, Catalogues and brochures GE Fanuc, SIEMENS, GPM International; Catalogues TITAN HEAVY DUTY MACHINE TOOLS, OPEN SERVICE, SIMTEX S.A

4. P.H. Joshi, Machine tools handbook design and operation (McGraw-Hill,New Delhi, ISBN 978-007-149435-9)

5. Perovic, Handdbuch Werkzeug-maschinen, Hanser-Wien, (ISBN 10;3-446-40602-6, 2005)

6. C. Teixido, J.C. Jouanne, B. Bauwe, P. Chambraud, G. Ignatio, C. Guerin, Guide de construction mecanique (DELAGRAVE EDITION Paris, ISBN 2-206-08224-1, 2000)

7. D. Prodan, Heavy duty machine tools (Mechanical and Hydraulic Systems, Printech Publishing House, Bucharest, ISBN 978-606-521-474-3, 2010)

8. D. Prodan, A. Bucuresteanu, A. Motomancea, E. Balan, Remanufacturing of heavy duty machine tools guideways plating with plastic materials (Revista de Materiale Plastice, Vol.53, Nr.4/2016, ISSN 0025/5289, pp 599-606)

9. R. Cotetiu, Issues on the use of polyamids in technological equipment construction (PRASIC'02 Brasov, ISBN 973-635-064-9)

10. H.S. Bawa, Manufacturing process - I (Tata McGraw-Hill, New Delhi India, ISBN 0-07053525-6, 2004)

11. A. Helmi, Youssef and Hassan El-Hofy, Machining technology machine tools and operations (CRC PRESS, ISBN 978-1-4200-43396,ISBN 978-1-4200-4340-2, 2008)

12. ***, www.halltech.com, www.aetnaplastics.com, www.tss.trelleborg.com
13. A. Bucuresteanu, Pneumatic-hydraulic accumulators. Use and Modeling, (PRINTECH Publishing House, ISBN 973-652-292-X, 2001) 